\title{
Morphological Derivations: Learning Difficulties Encountered by Public Secondary School Students in Amman/Jordan
}

\author{
Maha Zouhair Naseeb ${ }^{1} \&$ Majid Abdulatif Ibrahim ${ }^{1}$ \\ ${ }^{1}$ English Dept., Faculty of Arts \& Sciences, Middle East University, Amman, Jordan \\ Corresponding: Majid Abdulatif Ibrahim, English Dept., Faculty of Arts \& Sciences, Middle East University, \\ Amman, Jordan. E-mail: majidabd2@hotmail.com
}

Received: September 30, 2017

Accepted: November 7, 2017 Online Published: November 10, 2017

doi: $10.5539 /$ elt.v10n12p172

URL: http://doi.org/10.5539/elt.v10n12p172

\begin{abstract}
This study aims at investigating the difficulties encountered by public school students in Amman/ Jordan. The study raises the following questions: What are the obstacles that students may encounter in relation to the derivations? What are the causes of such obstacles? To achieve the aims of the study, the researchers manipulate two methods: A quantitative approach in which students of public secondary schools are tested and pre-tested in order to fulfil the reliability and validity of the results and a qualitative approach using interviews with teachers at the same secondary schools and one supervisor in Amman Third Educational Directorate (AL-Qwesmeh). The main results the study reaches can be summed up as follows: students are so poor not only in derivations and derivational suffixes but also in other linguistic topics. In other words, the problem of committing mistakes in derivational suffixes can obviously be regarded as being accumulative problem resulting from other problems which students are encountering in relation to, for example, parts of speech, word order or sentence patterns. Derivations and derivational suffixes should be taught in early stages such as the $8^{\text {th }}$ grade or $9^{\text {th }}$ grade rather than in the last ones like $11^{\text {th }}$ grade or $12^{\text {th }}$ grade.
\end{abstract}

Keywords: morphological derivations, learning difficulties, public school students, and suffixes

\section{Introduction}

No doubt, when looking thoroughly upon morphology, one would raise a plenty of inquiries as to whether morphology in general and morphological processes in particular deserve to be seriously tackled, investigated and explored. Perhaps, the response to such inquires can be summed up in one simple word: Yes! Morphology and all of its related theories, topics and details introduce themselves forcefully as a key-stone field whose linguistic frontiers are not self-sufficient by themselves, but they may be expanded to combine two other linguistic branches: phonology and syntax. So, it is this idiosyncrasy that makes morphology receive all of these linguistic overtones and this, in turn, resides in the significance and inevitability of studying morphology.

In morphology, derivation is the process of creating a new word out of an old word, usually by adding a prefix or a suffix. The distinction between derivation and inflection is that derivation may feed inflection, but not vice versa. Derivation depends on the stem forms of words rather than their inflectional endings, thus it creates new complex stems to which inflectional rules can be applied. The variation between inflectional morphology and derivational morphology is an old concept. Fundamentally, it is a matter of the means used to initiate new lexemes (derivational affixes among other processes) and those used to mark the role of the lexeme in a particular sentence.

In as far as learning derivations is concerned, one may notice that some school students in general are suffering from how words are formed and what morphological processes are appropriate to use not only among words, but also to distinguish a word from other ones. The problem, here, is rooted in students' intuition, i.e. most of derivational affixes are of Latin origin and this makes students' task impossible to know the meaning of these affixes and to use them properly. Accordingly, the current study has been conducted to cast some shadow on the derivations and the problems of learning them.

Although many studies have been conducted to show the importance of teaching parts of speech and other related grammatical topics to Jordanian students, there is still a gap in these studies to cover the field of derivation and derivational affixes that would contribute to solve some of students' difficulties in mastering 
English adequately. Thus, the present study is an attempt to offer students the proper ways to overcome their obstacles in learning morphological derivations and derivational affixes.

\section{Objectives of the Study}

The study serves the purpose of

1). Investigating the difficulties that public secondary students may face when dealing with sentences having the derivational patterns.

2). Looking seriously at the reasons behind these difficulties.

\section{Questions of the Study}

In order to accomplish the objectives mentioned previously, the study is set forth to provide answers to the following questions:

1). What are the obstacles that students may encounter with the derivations?

2). What are the causes of these obstacles?

\section{Some Theoretical Landmarks}

Morphology, like other disciplines, enriches with issues that require to be discussed. One of these issues is that what is termed as "morphological processes": derivations and inflections. Derivations are essentially viewed as one of the main categories of word formation. They are applied, side by side with inflections, to the two sorts of affixation (i.e. prefixes and suffixes) involving how words are formed. Fundamentally, the outcome of derivational process is a new word, e.g. globe: global: globalize (Anderson, 1992). In other words, derivational affixations tend to change the grammatical class (traditionally parts of speech) of morphemes to which they are attached. Derivational affixations, comparatively speaking, occur nearer to the root morpheme than inflectional ones do. Moreover, they are of independent, stable lexical meanings (e.g. dis-, mini ,sub...) (Mathews, 1991).

Katamba (1993) and Collinge (1990) go beyond discussing the nature and description of derivations and try to lead us to a heated debate among morphologists about " the legitimacy" of setting a distinction. They state that while all morphologists accept this distinction in some forms, it is nevertheless one of the most contentious issues in morphological theory. In fact, there is no consensus in the description and categorization of processes as inflectional or derivational. Linguists and morphologists working on the same languages would not be in total agreement on which processes should be taken for granted as inflectional and which ones are to be considered derivational. Surprisingly, derivation - inflectional dichotomy may, in some cases, exceed the limits of distinction and may become greater confusion, especially across languages.

In his attempt to discuss the term 'word-formation', and its pivotal role in morphological literature, Matthews (1991: 61) asserts that derivational morphology as well as word-formation are usually two faces of the same coin. In the former, it is not only to centre upon the grammatical processes of derivation, but also the creative derivation of new words that follow existing patterns.

Haspelmath (2002: 70) provides a detailed account of properties of both inflection and derivation. To him, "inflection is relevant to the syntax; derivation is not relevant to the syntax". Derivational meanings are somewhat more diverse than inflectional categories. They are characterized as being cross-linguistically widespread and being also of specific nature so that they are confined to a few languages. Languages have a lot of devices for deriving nouns rather than for verbs and adjectives, and thus both verb-deriving patterns and adjective-deriving ones are less numerous and diverse. Verbs are mostly derived from other verbs, whereas de-nominal and adjectival verbs are much less frequent than de-verbal verbs (Bauer, 2002).

On the mental ground, derived words, when formed, become independent lexical items that receive their own entry in a speaker's mental dictionary. As time goes by, they often take on a special sense that is not completely predictable from the component morphemes. Occasionally beginning students have problems determining the category of the base to which an affix is attached. For example, in a word like worker, the base (work) is sometimes used as a verb and sometimes as a noun. This may make it difficult to know which category occurs with the suffix (-er) in the word worker (O'Gray et al., 1996).

Aronoff and Fudeman (2011) pose certain questions as to why there is a distinction between inflection and derivation and as to what this distinction means. They answer that whereas inflectional morphology does not change the core lexical meaning or the lexical category of the word to which it applies, derivational morphology may or may not affect the lexical category of a word it applies to, and it changes its meaning. Inflectional morphology also tends to be more productive than derivational morphology. Despite the distinction made above, 
points of similarity may be exposed between inflection and derivation. Cross-linguistically, both of them can be expressed through prefixal, suffixal or non-segmental means.

The foregoing discussion of the nature of derivation and inflection paves the way to state that part of linguistic competence entails the ability to construct and understand words. Most of high school students know a great deal of words whose form and meaning are derived from those of other ones. Words as such are usually kept as individual items in the lexicon, i. e. mental dictionary. Nevertheless, there are other words that are constructed and interpreted by means of applying general rules to basic words. Morphology is, in a word or another, that discipline whose system is built up as a result of involving certain categories and rules in word formation and comprehension (O’Grady and Guzman, 1996).

\section{The Study Design}

This study adopts two different research approaches: a quantitative approach in which students of public secondary schools were pre-tested and tested in order to fulfill the reliability and validity of the results, and a qualitative approach where teachers of those students (of the same secondary schools) and a supervisor working in Amman Third Educational Directorate ( $\mathrm{Al}$ Qwesmeh) were interviewed individually in attempt to pinpoint and then to diagnose the nature and dimensions of the dilemma from which students were suffering.

\section{The Study Sample}

The study sample is composed of 60 students (18 male students and 34 female students) who were selected randomly from two public secondary schools for boys and girls. They were at the $12^{\text {th }}$ grade enrolling in the second semester of the academic year 2017. Moreover, three male teachers and three female teachers (holding a B.A. degree) as well as one supervisor (holding a Ph. D. degree) in Amman Third Educational Directorate (Al Qwesmeh) were selected to take part in an interview.

\section{Data Collection}

As hinted above, the study manipulates two research instruments; a pre-test and a test a done by students and an interview conducted to meet English teachers and a supervisor. As for the first instrument, students, first of all, were asked to answer the pre-test sheets which consisted of one give--example question of 25 items (see appendix (1)). After a while, they were also asked to answer the test sheets which included one fill-in-the blank question of 25 different sentences related to derivations (see appendix (2)). After the two tests had been done by the students, the researchers collected only 52 test sheets out of 60 .

The second instrument was an interview which had been conducted to cover six English language teachers at secondary schools for boys and girls: three males and three females. In addition, one supervisor was also interviewed in Amman Third Educational Directorate (Al Qwesmeh). All of them were really helpful with the researchers (see table (1)). A list of three questions was asked to the teachers and a supervisor centered on: first, the difficulties faced by the students when dealing with sentences containing derivational suffixes. Secondly, there are certain reasons behind initiating such difficulties.

Table 1. Demographic distributions of interviewees

\begin{tabular}{ll}
\hline Gender & No \\
\hline Male & 4 \\
Female & 3 \\
Age & \\
$35-40$ & 2 \\
$40-45$ & 5 \\
Nationality & \\
Jordanian & 7 \\
Work experience & \\
7 & \\
11 & 1 \\
13 & 2 \\
\hline
\end{tabular}




\section{1}

1

Educational Background

B.A. in English

6

Ph.D. in English

1

No

Gender

4

3

Female

40-45

Jordanian

\section{Validity and Reliability of the Instruments}

The pre-test and the test were given to a panel of experts to judge the extent to which they were valid and reliable. The experts were chosen according to their broad experiences in the field of linguistics in general and morphology in particular (see Table 2 below).

Table 2. Panel of experts

\begin{tabular}{llll}
\hline$\#$ & Name & Rank & Place of Work \\
\hline 1 & Dr. Saleh Miklala Fryhatt & Associate Professor & Al-Isra University \\
2 & Dr. Ola Al-Dabagh & Associate Professor & University of Petra \\
3 & Dr. Basil Hussein & Associate Professor & Al-Zaytoonah University \\
\hline
\end{tabular}

\section{Results of Data Analysis}

The results of the pre-test and test are illustrated via statistical column charts and pie charts. In column chats, the vertical dimension represents percentage, while the horizontal one stands for the mark ranges.

\subsection{Results of Pre-test}

It is of great importance to expose the pre-test and its results concerning the questions that have previously been posed in section 3 .

\subsubsection{Results in Relation to Question One}

As far as the male students are concerned, the statistical charts elucidate that those students are so weak in dealing with derivational suffixes. They score a very low percentage in words or expressions having these derivations: most of them score only marks ranging from 1 up to 4 marks. Then the charts demonstrate that the lower percentage is, the higher marks are obtained, whereas the higher percentage is, the lower marks are achieved (see Figures 1, 2 and 3). What reinforces the above-mentioned facts is that the results of school distribution (referring to archive marks obtained by the students of the same schools in the last ten academic years) exceed the possible limits of those of normal distribution (referring to marks obtained by the student sample of this study), and this, frankly speaking, is out of imagination in relation to the poor levels male students have in public schools. This proves two important things: First: male students are suffering from real obstacles and problems in tackling derivations, their rules and their use. Next: both the students' current and previous learning levels are still deteriorated though the current one, comparatively speaking, shows a little bit improvement, i. e. the students' current learning level is the lesser of two evils. 


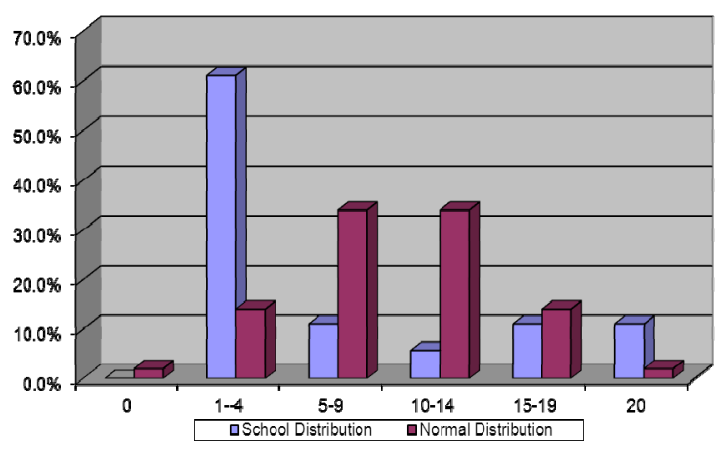

Figure 1. A column chart of percentage results of male students in the pre-test

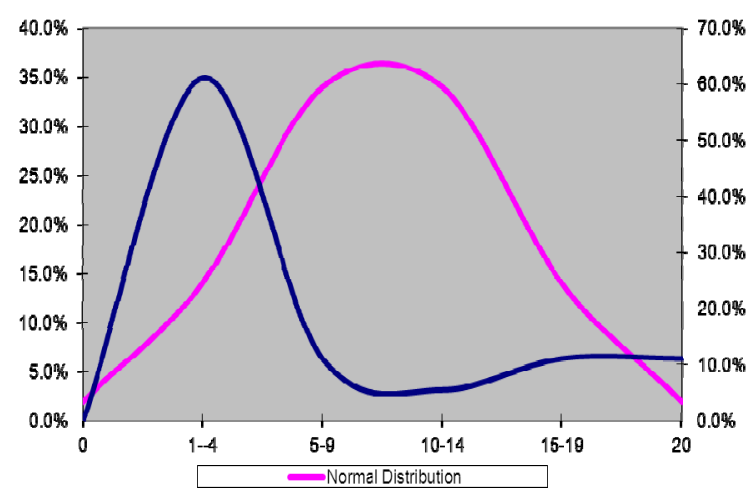

Figure 3. A curved chart of percentage results of male students in the pre-test
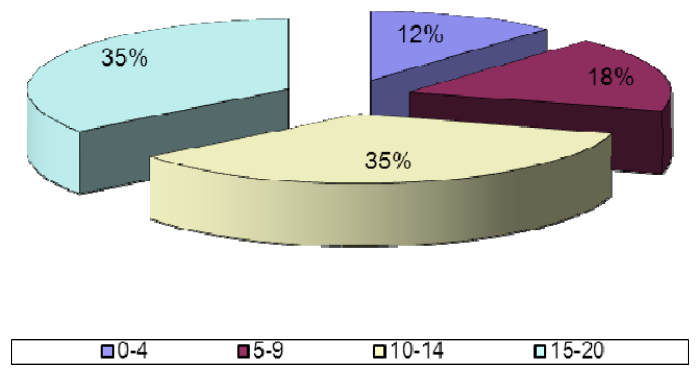

Figure 5. A pie chart of the percentage distribution of female students' marks in the pre-test

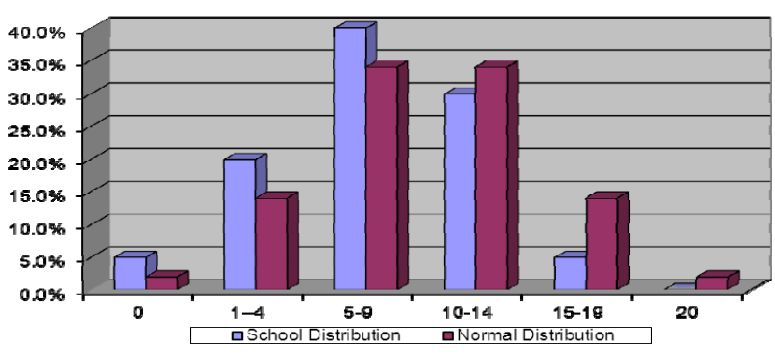

Figure 7. A column chart of percentage results of male students in the test

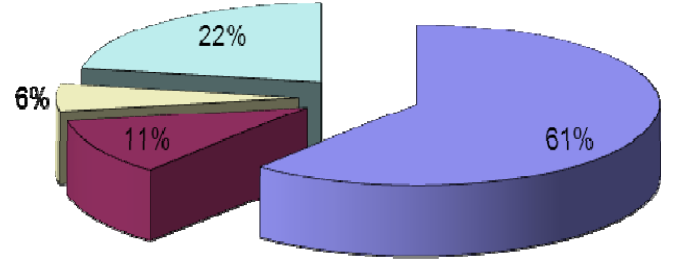

\begin{tabular}{|llll|}
\hline $\mathbf{0 0 - 4}$ & $\mathbf{0 5}-9$ & $\mathbf{0 1 0 - 1 4}$ & $\mathbf{0 1 5 - 2 0}$ \\
\hline
\end{tabular}

Figure 2. A pie chart of the percentage distribution of male students' marks in the pre-test

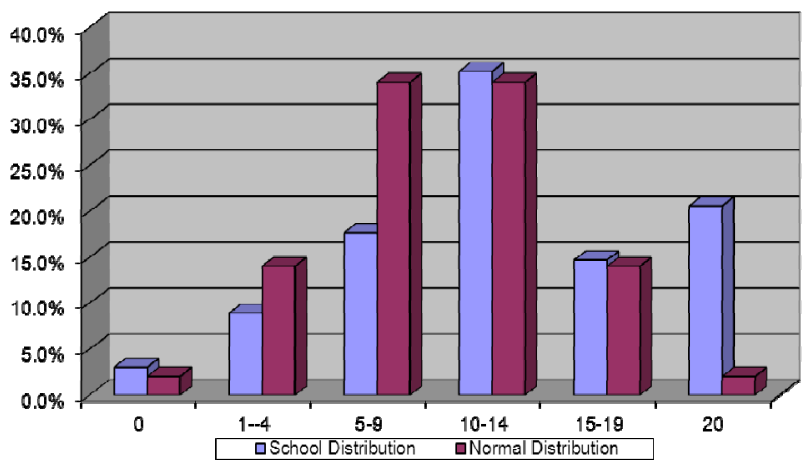

Figure 4. A column chart of percentage results of female students in the pre-test

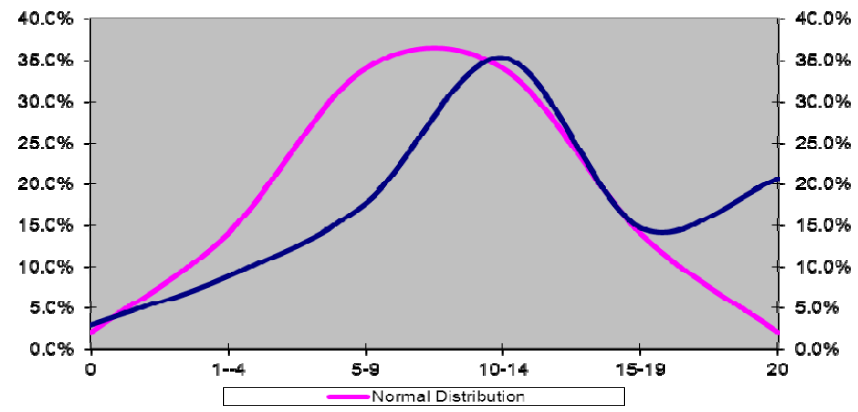

Figure 6. A curved chart of percentage results of female students in the pre-test

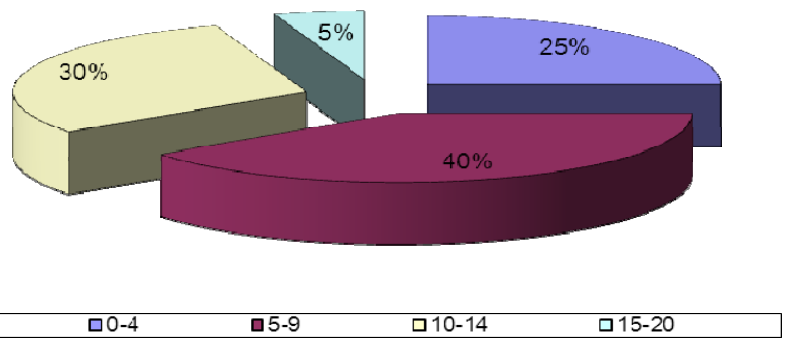

Figure 8. A pie chart of the percentage distribution of male students' marks in the test 


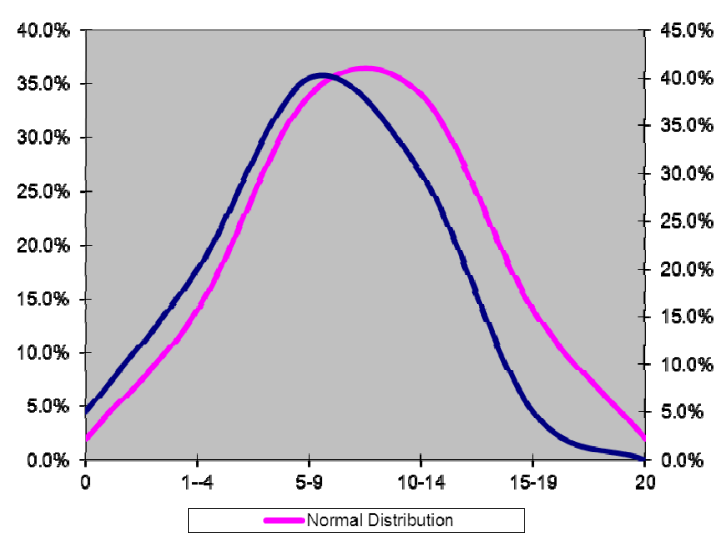

Figure 9. A curved chart of percentage results of male students in the test

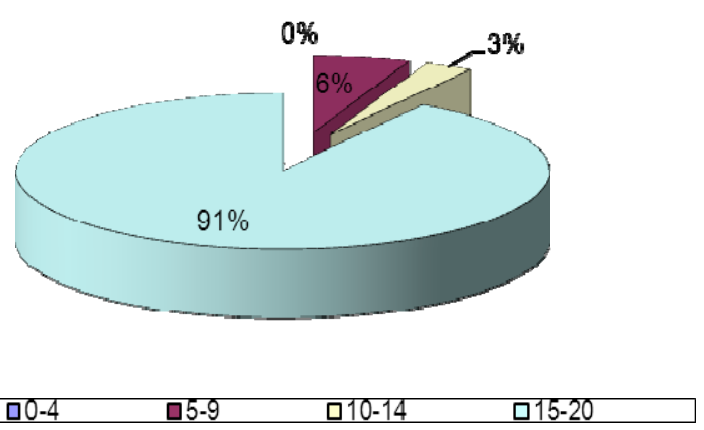

Figure 11. A pie chart of the percentage distribution of female students' marks in the test

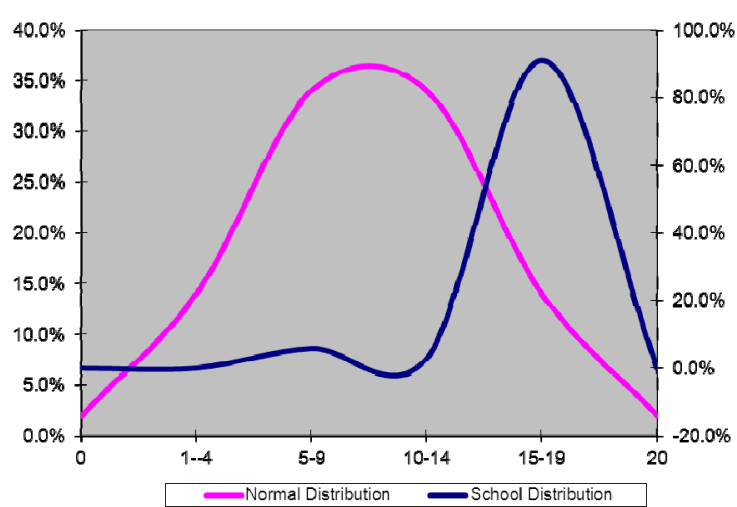

Figure 10. A curved chart of percentage results of female students in the test

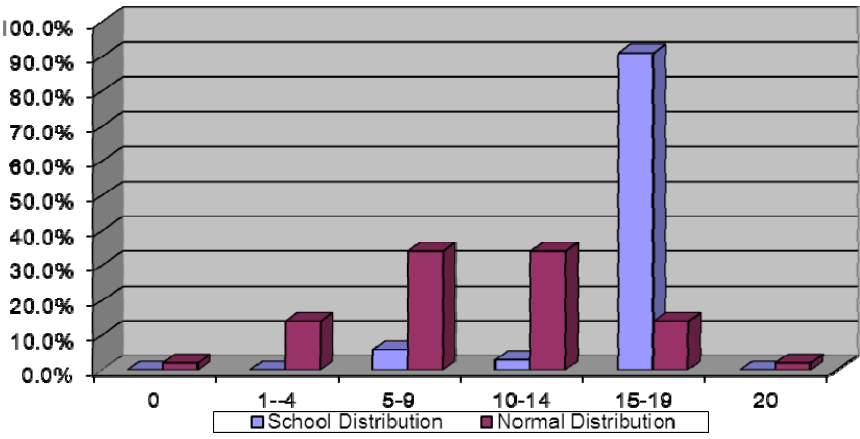

Figure 12. A column chart of percentage results of female students in the test

As for female students, the results are surprising in that they are completely opposed to those of male ones. The statistical charts indicate that marks ranging from 10 up to 14 score the highest percentage, and then those ranging from 5 up to 9 get a little bit lower percentage than the previous ones. Other marks reflect divergent percentages of low degrees (see Tables4, 5 and 6). What is worth-noting here is that both the results of school distribution and those of normal distribution are totally convergent, and this, in turn, supports the claim that female students are better in their morphological competence than male students as indicated in tables (4) and (6). In spite of having high percentages, female students still face some difficulties in relation to using and recognizing derivational suffixes in words.

\subsubsection{Results in Relation to Question Two}

It has been found via the results of the pre-test and their statistical percentages that the obstacles students face are doomed to certain causes. In the first place, that students fail to use derivational suffixes highly affect the grammatical form according to which words and expressions are constructed. For example, students do not know which grammatical item is supposed to be as a result of a suffix attachment. Next, failure of knowing the suitable derivational suffixes make students far from recognizing the grammatical class (parts of speech) of a word: whether a word is a noun, an adjective or an adverb.

\subsection{Results of the Test}

The test was conducted after four weeks. It is hoped that the results gained by the pre-test would be shifted into better ones. The researchers have given four lectures of two hours in which male and female students were taught detailed aspects of English derivations.

\subsubsection{Results of the Test Related to Question One}

A scrutinizing look at charts of the test (see below) shows that there is a growing tendency on the male students' part to improve their ability and capacity to tackle the use of derivational suffixes. That is, the male students' improvement is chiefly resulted from the fact that the researchers have done their best to teach those students thoroughly the use, the possible rules and patterns of derivations in general, and derivational suffixes in 
particular by virtue of manipulating a complete teaching method. For instance, figures(7), (8) and (9) demonstrate that marks ranging from 1 up to 4 score a very low percentage, whereas those ranging from 5 up to 9 and those ranging from 10 up to 14 accomplish a highly percentile ratio.

In relation to female students, the charts (10-12) elucidate that though there is an increase of the percentage in marks ranging from 5 up to 9 , and 10 up to 14 , a qualitative leap can be seen in marks ranging from 15 up to 19 in a way that the percentile ratio of the school distribution does not only exceed that of normal distribution, but it also scores $100 \%$. This is completely attributed to the following factor: the degree of readiness that is showed by female students to activate with the remedial lessons given by the researchers to improve their morphological performance.

\subsubsection{Results of the Test Related to Question Two}

In spite of a notable divergence of shown by both male and female students in dealing with derivations and derivational suffixes, the original problem is still present. It resides in the following points: the word roots are the causes behind such a problem in the sense that students are far from comprehending the morphological behavior of the roots. To straddle this gap, most, if not all, of students work upon memorizing a detailed glossary of such roots found at the end of the text book entitled Action Pack12. In a word or another, students, males or females, lack sufficient preparations to treat with how morphological patterns of English words are well studied and how derivational suffixes are consciously dealt with.

\section{Results of the Interview}

Attempts are basically made to reach the highest degree of objectivity and honesty when the interview has been conducted and managed. The nature of the questions raised is descriptively-oriented in that the interviewees frankly describe and identify the origin of the obstacles in front of which students encounter.

\subsection{Results of the Interview Related to Question One}

All of the interviewees agree that the obstacles students face are rooted in the sense that they are not very much interested in studying English in general. More importantly, vocabulary is not given priority on students' part to help and then contribute to support their capacity of dealing with derivations and derivational suffixes. What is actually astonishing is that the topic of derivations and its drills is not taught at the early stages like $7^{\text {th }}$ and $8^{\text {th }}$ grades, but at the last stages such as $11^{\text {th }}$ and $12^{\text {th }}$ grades. Ones again, the problem of neglecting the glossary found at the end of the textbook throws its glooming shadow on students in creating these difficulties.

\subsection{Results of the Interview Related to Question Two}

It has been revealed that the major causes resulted from such an educational decline in relation to teaching and learning derivational suffixes are attributed to the following facts. In the first place, students lack appropriate fluency that helps them manipulate derivational rules and parameters. Next, the question of proficiency totally disappears in connection with how derivations and derivational suffixes are supposed to be taught and lectured. Thirdly, students lack the least limits of the mastery over other linguistic skills and activities that reinforce, in a way or another, their ability to comprehend derivations.

\section{Discussions of the Results}

It is worth-mentioning to state that students of public schools actually encounter different morphological problems manifested in a great number of errors and mistakes committed in the realm of derivations and derivational suffixes. No doubt, such errors and problems occur most frequently and this shows how vast the gap is between students' morphological competence and their would-be performance. Moreover, students' obstacles of using derivational suffixes unveil a somewhat horrible outcome: there are repeated misuses of common derivational suffixes in a way that certain words would be created newly or would be absolutely distorted. This, accordingly, points out a profound, chronic collapse and deterioration on students' part in learning derivations and derivational suffixes.

The consequences of such collapse and deterioration increasingly seem to be too adverse to avoid because they represent a sort of learning fossilization, and it is hard to be of a short-term reformation. Moreover, these obstacles, which are classified as being the most serious, have the greatest effects on students' intelligibility. For instance, some derivational suffixes are attached to wrong words or syllables of words. Next, a misleading meaning can be easily recognized as a result of deformed words. Another effect is that there is an increase in losing the correct spelling of some derivational affixations.

As stated above, students' morphological performance has highly been affected by these difficulties. So, any attempts exerted for real remediation are doomed to failure. However, there may be a great chance of successful 
remediation when the drills and exercises are designed in a simplified and abridged way to meet students' poor level. For example, teachers tend to use very rigid and monotonous instructions when students are asked to do these exercises inside classes.

One of the different causes that lead to make obstacles in front of students of public schools in dealing with derivations and derivational suffixes is that some students may become under psychological pressure that prevents them from asking their teachers to clarify any point related to derivational processes. This psychological pressure may be represented in a form of embarrassment according to which students may be hesitant towards interrogating or repeating questions about the study material in general.

Other causes are resulted from specialized areas of derivations, i.e. some derivations are loan affixations borrowed from old or archaic languages like ancient Greek and Latin. Here, the problem is of dual nature: first, students, by all means, are forced to overcome such a problem because it is an essential part of their course material. Second, teachers are committed to straddle any material gap students may have because this is naturally part of teachers' assumed responsibility on teaching, educational and pedagogical grounds.

\section{Conclusion}

The study reaches the following conclusions:

1) The domain of morphological derivations requires a good deal of attention, interest and care students should consciously show.

2) Students are so poor not only in derivations and derivational suffixes but also in other linguistic topics. In other words, the problem of committing mistakes in derivational suffixes can obviously be regarded as being accumulative problem resulting from other problems which students are encountering in relation to, for example, parts of speech, word order or sentence patterns.

3) Teachers are not fully qualified in teaching English courses in general and English derivations in particular, and this forms the major part of the obstacles students face. Accordingly, this is partially attributed to the shortage, if not the lack, of training courses, teaching workshops and symposiums.

4) Students need a lot of intensified drills and exercises about derivations and derivational suffixes in order to guarantee that their morphological performance is going on the right way.

Educational supervisors have to diagnose truly the points of weakness that are accompanied with the teaching procedures and methods teachers of public schools have adopted in connection with derivations and derivational suffixes.

\section{References}

Anderson, S. R. (1992). A-Morphous Morphology. Cambridge: Cambridge University Press. https://doi.org/10.1017/CBO9780511586262

Aronoff, M., \& Fudeman, K. (2011). What is Morphology? (2nd ed.). Oxford: Blackwell Publishers Ltd.

Bauer, L. (2002). "What can you do with derivational morphology". In S. Bendjaballah, W. U. Dressler, O. E. Pfeiffer, \& M. D. Voeikova (Eds.), Morphology 2000. Selected papers from the 9th Morphology Meeting. (pp. 37-48). Amsterdam - Philadelphia, John Benjamins. https://doi.org/10.1075/cilt.218.04bau

Haspelmath, M. (2002). Understanding Morphology. London: Oxford University Press.

Katamba, F. (1993). Modern Linguistics: Morphology. London: Palgrave Macmillan.

Matthews, P. H. (1991). Morphology (2nd ed.). UK: Cambridge University Press. https://doi.org/10.1017/CBO9781139166485

O'Grady \& Guzman, (1996). "Morphology: The analysis of Word Structure”. In Contemporary Linguistics. London: Longman.

O’Gray, W., Dobrovolsky, M., \& Katamba, F. (1996).Contemporary Linguistics. London: Longman. 


\section{Appendix (1) A Pre-test Sheet}

Give one example for each of the following:

$>$ Noun $\rightarrow \quad$ adjective suffixes

1. (-al) --------

2. (-ive)

3. (-less) ------------

4. (-ous)

5. (-ite) ------------

6. (-y)--------------

$>$ Verb $\rightarrow$ noun suffixes

12. (-age)

13. (-er)

14. (-ment)

15. (-ant)

16. (-ee)

17. (-or)
7. (-ese)
8. (-ful)
9. (-ish)
10. (-ist)
11. (-ic)

$>$ Adjective $\rightarrow$ noun suffixes

18. (-ity)

19. (-ness)

$>\quad$ Verb suffixes

20. (-en)

21. (-ify)

22. (-ize)

Adverb suffixes

23. (-ly)

24. (-ward)

25. (-wise)

\section{Appendix (2) A Test Sheet}

Complete the following sentences with the suitable words derived from the words in the brackets:

1. Scientists that there might be a life on Mars soon. (estimation)

2. The -of fireworks goes back to Chinese. (invent)

3. When do you - to receive your test results? (expectancy)

4. Many candy advertisements are usually presented in an-------- manner in the TV. (attract)

5. Markets have different types of food which are-----------prepared from animal products. (artificial)

6. The----------system must be linked with the requirements of social and economic developments for any country. (education)

7. Jordan has------------of being a friendly and welcoming country. It is one of the safest places to visit in the Middle East. (repute)

8. Martha is very--------to eating fish; so she avoids eating it. (allergy)

9. Penicillin is one of the most important----------in the history of medicine. (discover)

10. People have started to buy----------produced meat and other kinds of food. (artifice) 
11. It is unlikely to----------unless you pay much effort on what you do. (successful)

12. Electricity is considered a great------------ (achieve)

13. Jack is a very active, intelligent and----------student. (organization)

14. Learning foreign languages is good for your personal-------------- (develop)

15. I cannot help you. You need--------------from a computer expert. (advise)

16. Would you---------my calculations? I think there is something wrong. (revision)

17. I am seeking for an------------heart surgeon. (experience)

18. I cannot-----------everything. I have just said: you must listen carefully. (repetition)

19. The company is pleased with your woks and is happy to give you a----------- (recommend)

20. Nuts contain useful------------such as oils and fats. (nutrition)

21. -----Amman is the most active city in Jordan. (economy)

22. His final----------was that he broke a new world record in running. (achieve)

23. At university there are many-----------courses which you can take. (option)

24. Most people-------------in big cities. (concentration)

25. Tom speaks English----------- (fluency)

\section{Copyrights}

Copyright for this article is retained by the author(s), with first publication rights granted to the journal.

This is an open-access article distributed under the terms and conditions of the Creative Commons Attribution license (http://creativecommons.org/licenses/by/4.0/). 